\title{
Traversing Sites of Affective Immersion
}

\author{
Alana Vehaba \\ ARIZONA STATE UNIVERSITY
}

This paper analyzes diverse moments of affective immersion, traversing the intergenerational legacies of the Holocaust, affective mobilization of Bangladeshi sweatshop laborers, and the conversations held in an undergraduate Serial Killers and Homicide course. What draws each of these moments together is the shared space of affect. The author synthesizes various understandings of affect and analyzes the ways in which affect theory bridges the mostly inarticulate places of memory, trauma, and imbibed violence.

\section{KEYWORDS}

memory, intergenerational trauma, affective mobilization, pedagogy 
Jiko looked out across the ocean to where the water met the sky.

A wave is born from the deep conditions of the ocean," she said. "A person is born form the deep conditions of the world.

A person pokes up from the world and rolls along like a wave. Until it's time to sink down again. Up, down. Person, wave."

-Ruth Ozeki, A Tale for the Time Being $(2017,194)$

Welcome. Before you are a set of meditations upon a few affective encounters that I have been moved to understand. Through each analysis we -you the reader and me the author, together now, for this - can catch a glimpse into the realms of the felt. The terrains today are the mostly inarticulate places of memory, affective listening, and imbibed violence.

Of interest in this article will be the ways in which we encounter affect within disparate spaces: as inheritance, and within memories, congregations, bodies, classrooms, and our very sociality. Affect has varying meanings and encompasses somewhat diverging ideas. In our definitions of affect we will focus firstly on affect's corporeality, moving then to its intersubjectivity, and, lastly, to how it can be mobilized socially and politically. Each of these definitions mirror the sites that we will then traverse. Site I is an examination of affect as part of the intergenerational legacy of the Jewish people. In this we will explore the affect that resides in the body and in inheritance. Site II is an analysis of a convening between Aklima Khanama, a Rana Plaza survivor, and the college students who hear her story. This allows us to examine how affect is shared and negotiated between people when trauma is spoken and a response is expected. And lastly, in Site III, we explore a class entitled "Homocide and Serial Killers" offered at a university, where we consider how affect can be a powerful tool if intentionally integrated into classrooms and pedagogy.

While you might seek guidance for each immersion, Immersion here means not just reading for affective moments, but experiencing the affective moments as much as you can allow yourself to. Let it surround you, breathe yourself into the 
moment, and then see what is there for you. Addressing the affective moments I offer demands an immersion that can feel like drowning-that leaves you breathless and confused, frustrated yet unguarded, and present to what Kathleen Stewart describes as the "spreading lines of resonance and connection that become possible" $(2007,4)$. I hope the immersion will elicit in you an alertness to that which is subtle, unsaid yet somehow, also, "there."

\section{Affect is}

For the sake of cohesion and in an attempt to provide conceptual moorings, we will begin with definitions. In the scope of this article, one cannot encompass the immense literature on affect-a theory that has captured the interests of fields as diverse as cultural studies, communication, media studies, gender and sexuality studies, sociology, psychology, cultural geography, anthropology, neuroscience, cognitive science, philosophy, politics and so on-and in this, no one can quite agree what it is. There is not a single, unified "theory of affect", as Seigworth and Gregg call attention to, but many "swerves and knottings" (2010, 5). Theories can overlap, compete, or narrowly elucidate finer and finer points. For our purposes we are focusing on how affect is corporeally experienced, how it is shared, and how it can be mobilized.

Brian Massumi, one of the most influential contemporary theorists of affect, offered the description that formed my first understanding of affect. Massumi states that affect is a "transpersonal capacity which a body has to be affected and to affect" $(1995,28)$. For Massumi, who generally embraces Spinozan-Deleuzean ideas about affect, affect is a visceral, raw pre-feeling, the shock that is felt before the electric chair has been turned on, a sense of pain before the feeling of pain. Affect, here, is a manifestation of the body's reaction to information in its environment. It is non-cognitive and unintentional, consisting of corporeal processes or states; intensities that influence thinking and judgments but are also separate from these. If emotions are considered subjective and signifying, affects here are unconscious intensities that are almost unprocessed but nonetheless affect us (27). Operating under a similar definition of affect, Nigel Thrift writes that, "individuals are generally understood as effects of the events to which their body parts (broadly understood) respond and in which they participate" $(2004,60)$.

For others, affect is not necessarily a pre-feeling, but it is that which is felt, shared, and intuited. Teresa Brennan, in The Transmission of Affect, draws upon biology to argue that the emotions and energies of one person or group can be absorbed 
by, or can enter directly into, another by way of a physiological shift that accompanies a judgment. These affects have the capacity to energetically enhance or deplete another affect (Brennan 2004, 6). Affect can be transmitted-sometimes biochemically, sometimes in thoughts- because "our energies are not exclusively ours" (6) and we are "not self-contained in terms of our energies. There is no secure distinction between the 'individual' and the 'environment'" (5). To Brennan, affect is continuously flowing between bodies, which allows affect to be shared. Social interaction and the sharing of affect shapes our anatomical makeup, alters our very biology (74). Seigworth and Gregg emphasize that attending to affect allows a subtler awareness of our relationality, because affect is something that "arises in the midst of in-between-ness: in the capacities to act and be acted upon. Affect is an impingement or extrusion of a momentary or sometimes more sustained state of relations as well as the passages (and the duration of passage) of forces or intensities. That is, affect is found in those intensities that pass body to body (human, non-human, part-body and otherwise), in those resonances that circulate about, between and sometimes stick to bodies and worlds, and in the very passages or variations between these intensities and resonances themselves" $(2010,1)$. If emotion is likened to an object possessed by a subject, affect would be that which defies possession, because affect does not reside solely in one subject, body, or sign. It is that which is between us, that which we know about in messy, and sometimes muted ways. In this way, affect interrupts the Western conception of ourselves as discrete beings, isolated, and impervious.

For our impending immersion into sites of affect, I shall draw upon descriptions of affect that focus not just on affect's corporeality and intersubjectivity, but on how it is mobilized socially and politically. It is both something done unto you and something you can create. One can harness the potential of affect without ever naming it as such. Sara Ahmed writes that affects are not autonomous, but instead, "work as a form of capital: affect does not reside positively in the sign or commodity, but is produced only as an effect of its circulation" (2004 a, 120). National and collective discourses are shaped by emotion, and it is this that sustains and preserves the link between ideas, values, and objects, such as how "Arab, Muslim, Middle East" following 9/11 was affectively linked by the emotion of fear of the "terrorist" (2010). Even if it is modified by 'could be' or 'potentially' or 'found to not be,' the affective link is there and remains there, and was used effectively to rally popular support for entering into the 'War on Terror.' Dian Million considers affect an intensely potent force, separate from emotion. Emotions are 
simply "individual expression, affect is the larger charged sociality of emotions, traces of a vitality being prior to and not reducible to thought. ... Affect eludes, present before and beyond any singular consciousness. Affect has transformative power wherein building intensities electrifies moments of potential” $(2013,49)$.

These definitions give you a sense of the layered terrain that we will be walking through in this article, and to outline a bit of the process by which I have come to my own definition of affect. It is that moment of pause when you enter a room and get a sense of tension (Brennan 2004). It is the look that passes between friends or between strangers, where, still silent, you suddenly understand something about them. It is your stomach tightening, your heart racing, and it is, equally, a feeling of looseness in your limbs when your body knows itself to be safe. I know it as that feeling on my chest, that heaviness of a heart cracking open, pushing through. What we have so far then is a sense of affect as an intensity, affect as shared, received and transferred, and, although it is often divorced from language or interpretation, or intent, it nonetheless potent and, importantly, malleable. There exists a sociality of emotion (Ahmed 2010) - affect is not solely internal, nor does it exist externally only when expressed. It is the experience of the invisible (though sometimes perceivable) space that emanates through, between, and of the material world. Affect often exists prior to and beyond words; it inhabits liminal spaces between words; it inhabits liminal spaces between words and their definitions, between emotions and feltness, and between you and me. And when manipulated, affect can be deployed politically to mobilize warfare or propogate hate (Ahmed 2004). But what the idea of affect ultimately allows us to see is that we are inherently constitutive, that we share certain states of being, and that our subjectivities and perceptions are deeply influenced on subtle levels by one another's affective state. Ahmed writes that in order to study emotion one "begins with the messiness of the experiential, the unfolding of bodies into worlds, and the drama of contingency, how we are touched by what we are near" $(2010,30)$. And so together, let's walk through some moments and memories, to sites of affect.

\section{Site 1 \\ Based upon, living with, building through}

On Pesach, Jewish people tell a story of liberation from slavery. As we narrate it, we oscillate in voice and tense and location-at once telling a story that is somewhere between Jewish history and Jewish mythology. Simultaneously, Jews assert that it is our personal story, our personal history. We are commanded to tell the story of Passover as though we ourselves were enslaved in Egypt, imagining our bodies subject to whip and lash, and our babies to infanticide. It is I who broke 
the chains that gripped me, I who left Pharaoh and his army to drown in the convulsing Red Sea. It is us, we recite each Passover, who crossed the Sinai desert into freedom, who felt the desert wind burn our faces as we turned, together, toward our freedom. The slavery is mine and it is ours, and the freedom, too, is mine and it is ours.

This is a curious habit of the Jewish people, characteristic of how we integrate the many histories of Jewish persecution into a legacy we come to inherit and then transmit. These stories that we did not experience become the words and deeds and moments by which we frame ourselves. When we claim the stories of our ancestors as our own individual stories, we collapse the past and reject linear, self-centered time. Thus, as a Jew, the story of Exodus is my story, and as a Jew, the story of the Holocaust is my story. Felman and Laub contend that the Holocaust "is an event without a witness" (1992, xvii), because the Nazis enveloped their Jewish victims in delusions as to what was actually happening, because they destroyed the evidence of their genocide, and crucially, because the world does not have the conceptual framework with which to make sense of the enormity of the Nazi crimes. The after-shocks of this historical trauma, as it registers in the minds of the survivors and those who struggle to hear their testimony, is a "crises of witnessing" whereby true testimony becomes almost impossible when the Nazis destroyed the possibility of a "community of seeing" (Felman and Laub, 211). Grace Cho, in Haunting the Korean Diaspora (2008), suggests that trauma can be distributed through a whole cultural diaspora trans-subjectively, through an unsaid "haunting," the circulation of what cannot be assimilated $(2008,11)$. According to Gordon, the difference between trauma and haunting is that "haunting, unlike trauma, is distinctive for producing a something to be done" (1997, xvi). Modern Jews are entreated not just to reenact these histories, but also the affect of the histories. If affect is an "impingement" as Seigworth and Gregg (2010) tells us, that resonates across time, then affect is also the intent of the telling of trauma. In other words, the intent of the transmission of these stories is the affect, the impact and the intrusion of these stories into the subconscious of those inheriting them. In such a way, it is affect that is carried within, and carried through generations. Affect helps us become our own witnesses.

And it is for this reason, for this momentum created by the affect, that the Jewish tradition entreats us to place ourselves in these moments, to be the Jewish people in the desert, and be the victim killed in the Holocaust. Indeed, the Haggadah 
HaShoah (the telling of the story of Exodus), takes the commemoration a step further, urging us to recite together on Pesach: "We couldn't believe it; we didn't want to believe the evil end the Nazis had in store for us...The Nazis fed our hopes with lies and deception. Their program was called 'Resettlement to the East' as we were packed into cattle cars. Finally, we were told to strip for 'delousing.' We waited for water from the showerheads, but no water came. It was gas-farm pesticide Zyklon B gas-gas that ended our lives" (Adelson 2005,1). It is us who went through Egypt-do you feel the sun burning your cheeks? And it is us who entered the cattle car, never to return home. Do you feel the air tightening as the doors close around us?

It is rare to find a Jewish American family that can claim to be untouched by the Holocaust. We also cannot. My great-grandfather, that is, my mother's grandfather, came to the US when he sensed hostility in the air at home. He was born in a shtetl in a place that no longer exists, somewhere we now know only vaguely as the fickle border between Russia and Poland. He immigrated to New York in the early 1920s, well before the Holocaust. He worked as a tailor and struggled to bring his family to the United States while raising my grandmother and her siblings. He had heard his village was raided; he had heard rumors that Jews were their targets. He struggled to get his siblings and cousins and parents out, to obtain all the visas (those magic documents that allow mobility and thus security), but he also never imagined that it would all move so quickly or that his people would meet such an efficient end. He did not succeed in saving his family. When my great-grandfather learned that his entire family-every single member-was murdered in the Holocaust, he had a heart attack, right then, right at that very moment. He died instantly, this great-grandfather of mine. The telegraph, I imagine, fell limply from his hands.

When other children marveled at the strangeness of their existence and wondered why they were brought into this world, I never needed to speculate. My parents, from before I can consciously remember, told me that the reason I exist is because of the Holocaust. I knew this before I knew what it meant, before that word would evoke piles of naked bodies strewn across rooms and the eyes of skeletal men and women, their features protruding and their skin waxen-and yet, I was told, it was for them that I was born. You see, my mother explained to me that in planning our family, my parents decided that they wanted three children. My brother and sister, both elder to me, would be like my parents in body, and perhaps in mission, when my parents left this world. And I, the youngest, was brought to earth to replace a Jewish person murdered in the Holocaust. That was always the word she used to describe the reason that I am here-that I "replace" them. "So that the Jewish people continue," she said, "so that the Holocaust will never be 
forgotten." These two things are always in tandem. Aurora Levins Morales writes about how we hold our ancestors' past within our bodies, that their histories we "take in like heavy metals, to reside in the slow moving, fatty tissues of our sense of self" $(2013,41)$. If that is so, does the one I replace also move within me? Their ill fate or the potential their life once held?

I find I cannot remember a time when I did not know about the Holocaust, nor can I remember learning about it for the first time. For me the world always held the specter of the Holocaust victim, and humans always had the capacity for genocide, for determined and inventive and efficient evil. Searching for recognition, searching affectively for the faces and personalities of the Holocaust specters (Gordon 1997), I took it upon myself as a child-or did my parents encourage it? - to consume everything I could find on the Holocaust. My favorite books were first person narratives. Anne Frank, of course, became an intimate friend; but so too were the stories of Rebecca's Diary, her musings on the fences, and oh, that moment when Elie Wiesel gave up on God and refused to observe Yom Kippur. Primo Levi, I felt, should only be read if hungry.

When I was around 4 or 5 my favorite book was The Number on My Grandfather's Arm by David Adler (1987), a children's book that my mother uses to introduce $4^{\text {th }}$ grade Jewish students to the Holocaust. It tells the story from the point of view of a granddaughter who notices strange markings on her grandfather's arm while he washes dishes. Normally, her grandfather wears long sleeve shirts- always, in fact, he has his arms covered. She asks him what those strange numbers are, and he hesitates. He has a conversation with her mother, and his daughter tells him, "It's time you told her." And so, he sits his granddaughter on his lap. He speaks softly. Describes a time before Adolf Hitler, a time when he played with his sisters and brothers and friends in the fields around his village, all sunlight and laughter. He then describes the changes that started once Hitler started speaking: the loss of jobs and rights, the synagogues destroyed, the beatings in the street. He talks about being rounded up, nearly suffocating in the cattle cars, starved and made to labor in the camps. How he became a number, how his whole family, all his friends, didn't leave those camps alive. The granddaughter holds his hand while he talks and they both have tears in their eyes. After he finishes speaking they sit in silence. In the end of the book she urges him not to hide the numbers, not to be ashamed because he had done nothing wrong: "Grandpa hugged me. Then he looked at me and smiled. He wiped his tears and said, 'Let's take care of those dishes now.'” 
I wonder now why I found that particular telling of the Holocaust so compelling. Perhaps it was because the granddaughter's position, her role in the intergenerational transmission of trauma and affect was so clear. She was there to receive, believe, and comfort. Tell him not to be ashamed and to imply that she will keep his story now. Because it is her story too. The affective transmission was complete. She held him, she held all of them. In reading all these Holocaust texts so young, I suppose I was trying to live by the indictment of all the survivor-writers: do not forget this "because if we forget, we are guilty, we are accomplices" (Wiesel 1986, 118).

Primo Levi, a survivor of the Holocaust, describes a dream he had while imprisoned. He is with his sister and with friends, surrounded by people. They are all listening to him and he is telling the story of Auschwitz, the hunger and the lice and the Kapo who beat him. He writes that in this dream he feels an intense pleasure "physical, inexpressible" $(1969,60)$. He is glad to be finally home and among some many friendly people, and able to tell them his experiences. And yet, slowly, he notices that his listeners are not listening to him at all, they are indifferent to his story, and they act as though he is not there. His sister, he writes, looks up at him and goes away without a word. With this dream, he describes that "a desolating grief is now born in me, like certain barely remembered pains of one's early infancy....my dream stands in front of me, still warm, and although I am awake I am still full of its anguish: and then I remember that it is not a haphazard dream, but that I have dreamed it not once but many times since I arrived here, with hardly any variations of environment or details. I am now awake and I remember that I have recounted it to Alberto and that he confided to me, to my amazement, that it is also his dream and the dream of many others, perhaps of everyone" (60).

It is us who haunt him. The idea that he will be unheard-that we will not hear him-is what keeps him up at night while confined. Leah Gilmore asks, "Where does harm done in the past end? The power of trauma to outlast the duration of its infliction is crucial to the sense of wounding that makes the term so resonant. For example, as a historical event the Holocaust is over, but its power to harm is not" (2001, 29). Its power to harm is not over. Marianne Hirsch argues that we can never stop mourning the Holocaust, because of the "endlessness of the tale" $(1992,23)$ and the incomprehensibility of the Holocaust destruction. This is a profound idea-that we cannot stop mourning because we cannot fully understand why it happened. So, the children of Holocaust survivors-and, I would extend, most post-Holocaust Jews-live in the shadow of loss and with unbearable memory. Hirsch calls this process post-memory and argues that post-memory 
is a constitutive force in the makeup of children of the survivors. It is they who must block the work of forgetting, whose life is dominated by memories that are not their own and who live with "a fragility, a woundedness that defies all healing" (25) because all they know is fragments of a history that they cannot take in. For us then, there is only ambivalence. We live within inherited frames of remembrance, seeking communities of memory (Owen 2010). And yet the imperative therein is not just to remember, but it is to watch, to be wary, to seek, and to transform. Because we hope, deeply, for Maya Angelou's missive: "history, despite its wrenching pain/ Cannot be unlived, and if faced/ With courage, need not be lived again." (Angelou 1993). Not by us and not by anyone.

\section{Site II \\ Now you hear me}

There is a tightness in her face as she prepares to tell us her story, and when she speaks she looks at a space above our heads. The translator watches her closely, then speaks for us her quiet words. She doesn't look at the translator but watches us as we listen.

She is sitting on a raised platform with a bottle of water next to her, wearing a kamiseof every color. Her audience is nearly 150 college students; the room is crowded with people who fill the chairs and line the walls. Her translator says these words:

"My name is Aklima Khanama and I am 20 years old. I started working at the garment factory when I was 14 ...I began working at Rana Plaza on January $3^{\text {rd }}$, 2013." Her father was ill, she explains, so she started working to support her parents and four siblings. "We made clothes for Wal-Mart and Children's Place. Managers would say "This is for Wal-Mart, you need to make it beautiful."

"If I spent too long in the bathroom, they would pull my hair, kick me off the stool, call me 'whore' or say 'your parents are children of pigs' or many other kinds of bad language." The translator pauses, but only briefly. "My normal workday was from $8 \mathrm{am}$ to midnight. Sometimes they kept us there until 2am or 3 am. I worked 7 days a week. The whole time January $3^{\text {rd }}$ to April $24^{\text {th }}$, I was never given a single day off." 
April $24^{\text {th }}$ hangs in the air. The student next to me shifts in his seat. I feel nervous for Aklima. I suddenly don't want her to speak. I feel as though she'll hurt herself by telling us this story, and I find that I'm holding my breath, thinking, "it's ok, you don't have to tell us. I believe you anyway. It was only a year ago; it's too soon to tell us. You don't have to." She continues, and her voice is flat, her eyes hovering above the audience as she speaks, and, again, she watches us closely as we listen to the translation of her words, "On the morning of April $24^{\text {th }}$, the management forced us into the factory using physical violence and said that there was a shipment of 24,000 pieces that needed to go out. People had noticed cracks in the wall the day before, so we went home early, but the $24^{\text {th }}$ they-they said we would be fired and not paid for a month if we couldn't meet the target. They forced us back inside. Soon after we started working, the power, it went out. Then the generator went on."

Aklima looks at the translator, who then continues, with the same bloodless tone. "Moments later the building collapsed. A machine fell on top of me. I was trapped under it. A man next to me died immediately. A . . . a . . beam went through him. I saw it. The roof, then the machines, it fell on me . . I was stuck under the machine for 12 hours until they found me. I waited for them. I had a head injury, my chest hurt, my hip hurt, my ankle hurt. I can't work now." But she survived, 1,134 people did not.

Aklima takes a breath. She looks at us, and then she speaks to us in English, directly, without the translator. Her voice still without inflection. "Now you hear my story, are you going to help me?"

The room is silent. Collectively waiting, it seems. She waits too. The activist from Bangladesh who will speak after her, leans over and whispers something in her ear.

Another minute-could it have been two?-in that terrible silence. Then she asks again, with the same words, "Now you hear my story, are you going to help me?"

There is a shuffle, a nervous laugh from the girl next to me, and then someone says "Yes" weakly and the students begin to clap, nodding and saying, "Yes. Yes!" She watches us and is silent. Does she see in the sea of students before her the many, many garments that she stitched together, joining sleeve to torso, leg to waist? Were other students unsettled by her gaze? Was she unsettled by ours? Was affect what was shared in that space between us? Was that why I suddenly felt so uncomfortable for Aklima, a corporeal reaction to her sharing a trauma 
that is both intimate and political? Considering our above definitions, it is exactly affect that was transmitted and received then, flowing inside that room, inside those shifting in discomfort, inside her disquieting gaze. Affect is what fills that space-between that is generated by the sharing of trauma, that which creates subtle and nonverbal felt links between the sharer and the receiver.

Now, the question becomes: If we are all sharing a "something" in that room, can affect mobilize us to "help" Aklima as she so directly asks? Aklima has come to Arizona State University from Bangladesh through the United Students Against Sweatshops (USAS), as part of the national "End Deathtraps" workers' tour, which urges universities to divest from apparel companies that refuse to sign the Bangladesh Safety Accord (BSA). When I see her, it is her second time speaking in front of an audience, and an organizer tells me that she has 22 more schools to speak in before she returns to Bangladesh. Their most recent campaign agenda is to place pressure on the VF corporation, which has over 100 factories in Bangladesh and yet refuses to sign the BSA, thereby refusing to ensure that their factories are safe enough for workers to enter without fearing for their lives.

The president of ASU's chapter of USAS, Jonathan London, a Transborder Studies senior, speaks after the Bangladeshi women, declaring that, "Students have the power to change what is happening to garment workers in Bangladesh. The University is tied to these issues and, being tied to these issues, they hold a responsibility in being the change for them. ASU can certainly be the solution!" (Bankhead 2014). The event culminated in our signing a petition that urged ASU's president Michael Crow to "Make Alta Gracia ASU's spirit tee! Help us be a world changing university and make strides toward living wages in the garment industry by supporting Alta Gracia and getting their brand seen by students."

Her trauma moves us to sign a piece of paper? Perhaps that is too cynical a reading, perhaps it is unworthy way to describe the affect that was shared in that room? Because with affect we do need to leave open some ambivalence, some space for different readings. Maybe something subtler happened in the student audience, maybe that silence was not a silence of hesitation to act and support her, but a silence in which they let it hit them, let her narrative and presence affect them. Maybe they were running all the clothes in their closet over in their mind, wondering if anything was made in Bangladesh. Maybe they were overwhelmed in that moment with how thoroughly capitalism and imperialism have 
destroyed lives, and how profoundly it alienates us from each other. You never know, because, as Cathy Caruth claims, "trauma itself may provide the very link between cultures" $(1995,11)$. Because we slowly come to recognize that history, like trauma, is never simply one's own, because "history is precisely the way we are implicated in each other's trauma” $(1996,7) . "$

I felt uncomfortable watching Aklima speak because it felt indecent that she had to come here and narrate that awful day in order for us to care about her, or about the multitudes of Rana Plaza victims, or the hundreds of thousands who currently labor in an industry that cripples their bodies and exploits their poverty. Aklima's story felt too intimate, too fresh, too soon to be spoken. There was a fragility in the way she held her body, the waver in her voice as she spoke. Yet we must also situate this moment and my reading of it within the question that Sneja Gunew poses (2009), namely, to what extent can we think meaningfully about affect outside of the concepts, terms, and theories of mind of Western psychoanalysis? Can affect be read-and assumed to have been read accurately-as the "expressive armory of the human body" (Thrift 2004) if the speaker of 'trauma' is non-Western? When we view emotions as discursive public forms, deeply embedded in specific cultural logics of expression and interiority, we must ask if affect is decipherable, if it is translatable, across cultures. Western theorists see trauma as a "wound," as a self-altering, self-shattering experience of violence that is not quite representable, that exists slightly separate from memory and language (See Caruth 1996, Seltzer 1997, Leys 2000, Casper and Wertheimer 2016). Is trauma to the Bangledeshis conceived of as a "wound"? Perhaps, but perhaps not. But we do know a few things: signing a petition may have given students "unearned and incongruous spiritual uplift" (LaCapra, 2000: 51) by feeling that they are part of altering the deadly and exploitive garment industry, but it doesn't feel like an adequate response to Aklima's question that began with "now you hear my story."

I felt that we were still exploiting her-this time behind a microphone, before from behind a sewing machine-and wondered, continuously: what does it do to her to perform her trauma? I name this a performance because within the telling is the intention: I speak my pain, so that you will care about me, so that you will support me. Aklima and the organizers of the USAS are employing her story, instrumentalizing it in order to produce a certain affect. Yet in doing so, she must balance the audience's expectations and desires, such that it moves us to support her cause. Leah Gilmore writes that narrativizing one's story is an act of self-production, and "testimonial projects require subjects to confess, to bear witness, to make public and shareable a private and intolerable pain" $(2001,7)$. Because even as she produces herself, we produce her. She gives both her story and her feelings as an offering (Hochschild 1983), and it gets converted, warped into currency 
in an affective economy, whereby feelings do not reside in subjects or objects alone, but "are produced as effects of their circulation" (Ahmed 2003, 3). It may cause, for some, what Dominick LaCapra refers to as "empathetic unsettlement" to denote an affective involvement in which one feels for another without losing sight of the distinction between one's own experience and the experience of the other, "without taking the place of-or speaking for-the other or becoming a surrogate victim who appropriates the victimizers' voice of suffering" (2000, 51). It is when her audience understands Alkima's sharing as an encounter-a chance for her to meet us and us to meet her (not just consume her), that affective listening can take place.

Kelly Oliver also examines the question of response, and, by proxy, the question of recognition. Oliver takes the position that those othered by (and oppressed within) dominant culture seek not only, and not even primarily, recognition by that dominant culture, but something "beyond recognition" (Oliver 2001, 78). Recognition, in this definition, comes from the idea that only those with power can confer recognition, and thus granting recognition reinforces differentiated and hierarchicalized power. She sees the need for one to demand recognition as an indication of the "pathology of oppression" $(2001,23)$-that those who demand recognition see that it can only be given by those outside and with power over them (as in Hegel's master-slave dialectic). She suggests instead that one can bear witness to "a truth about humanity and suffering that transcends those facts" (2001, 80). Bearing witness, she advocates, is a powerful alternative to recognition, in that it re-conceives the subjectivity of the oppressed person and reorients the subject position of the oppressed person as one able to structure the "addressability and response-ability" of the other $(2001,105)$. In coining the phrase "response-ability," Oliver asserts that all subjects are necessarily and inherently social, and thus necessarily and inherently obligated to the other. In this, everyone has the ability to respond, to witness, and to meet.

But in order to hear Alkima's story, in order to listen to it, we must be willing to be "at the edge between fear and outside, on the edge of my skin, listening, asking what new thing I will hear, will I see, will I let myself feel....I try to say to myself: To acknowledge the complexity of another's existence is not to deny my own" (Pratt 2001, 69). 


\section{Site III \\ The Most Prolific Serial Killers}

I wonder what it feels like to stand before 192 students and teach them about serial killers and homicide? To hold in your hands the way they consume that violence? I know what it feels like to TA that course-that is, I know what it feels like to sit silently in the amphitheater-like classroom and watch the faces of 192 students as they learn about serial killers, to help when technology problems inevitably arise, and to ease student's concerns about their attendance or quiz grades. I also know what it feels like to listen to the lectures, an hour and a half twice a week, about which serial killer wore the skin of his victims (that would be Ed Gein), and who specifically targeted sex workers in Seattle, killing 71 women before he retired (Gary Ridgeway, of course). Held in the beginning of my graduate studies, this class, the students taking it, and the professor teaching it, got me thinking.

The pedagogical observation that struck me in this class was that, despite the obvious and deeply disturbing nature of the course material, it was taught in such a way that the affect, the feltness, of the material was ignored. Students memorized paraphilic behavior, the who-did-what perverse sexual act to whose decaying corpse, but there was no discussion of what it felt like to have these killers dwell in your head at least long enough to answer test questions about them. How much space did these killers take up in the minds of these students? Did the awareness of them leak into other parts of their life? Do the students find themselves more wary of people after learning this material, and are we to consider this a triumph if they are? The objective of the course was simply to learn how to profile serial killers, mass killers, and spree killers; to learn their individual stories, their unique brand of evil, their impulse to kill, and their eventual arrest and trial. Through powerpoint slides, every day we met a new killer.

Near the end of the first class on the first day, the professor gave the students a warning, saying, "Listen, so, some of this is going to be hard to learn. If you find yourself feeling things, then take the time after class to go get a smoothie or watch a non-crime related show. Hang out with your friends, take care of yourself. You know, self-care." This was the last time the professor mentioned that this material might become part of you in a way that was uncomfortable, and yet, each day that I walked into the room I felt a wave of wariness about what I would learn that day. I resisted letting new stories enter my mind. I began to develop different methods of arming myself against this class. Some days, discreetly, I would sit in front of the students, in my little corner at the front of the room, and position myself so that I would not be forced to face the presentation on the screen. I would instead watch the faces of the students as they watched the 
movie. And, to be honest, most of the faces were impassive, blank. They no longer cringed like they used to, they no longer watched the movie with an expression of disgust, their bodies tense. They simply sat, notebook in hand, and jotted down the facts they were mostly likely to be tested on. Over the course of the semester I began to feel like I was the only one disturbed by the content and grieving the loss of life we daily described. For most of my students, this class was a way to be a more informed viewer of Criminal Minds, Cold Case, CSI New York, CSI Miami, Dexter, Bones, Law and Order: SVU, The Following, The Killing, etc. Maybe the students who did have nightmares from the material couldn't find a way to speak it.

To me, urging the students to practice self-care once, but framing the class in such a way that it ignored the affect of the material, was a dangerous pedagogy indeed. Because listening, as Megan Boler remarks, is "fraught with emotional landmines" $(1999,179)$. She writes that students have learned emotional selectivity and inscribed habits of inattention to that which brings them discomfort. I would extend that by noting that it is, of course, not simply the students who are selecting what to hear because they don't want to feel. Dahlbeck (2014) asks us to understand that the goal of affective pedagogy would not be "academic success," but something else entirely:

Affective learning pertains to the idea that generating (and being sensitive to) bodily affects- understood in terms of force and capacity rather than emotion or feeling (Watkins, 2006, pp.270, 273) - can be thought of as the very hotbed of learning, where learning is understood as a creative process of experimentation with an exploration of one's bodily capabilities- of exploring the as of yet unknown - rather than as a purely reflective process of developing one's supposed natural ability to recognize and identify that which is already known. $(2014,20)$

The classes I have taught (on racial politics in the US, on genocide and human rights) often have violence in them: both in subject matter and in subtle, interpersonal dynamics. But classrooms can also be "productive spaces in which to name, distribute, produce, and practice expressive resources that enable a witnessing, and which establishes living memories and admits the dead into one's moral community" (Simon and Eppert 1997, 187). Returning to Massumi's definition of affect, we see that affects are often ungovernable, and that affective responses are autonomous; they live in the terrain as forces of energy. Negating the affective implications of the course material-refusing to allow that it does pull us 
affectively- continues that tradition of dismissing one's emotions as a kind of knowledge. Because students are not sieves where they can let in the information and strain out the affective impact of it, what affect theory tells us most concretely is that even if it is not conscious, the affect is there, and it affects.

This also misses the opportunity to form a pedagogy around affect, to use affect to propel learning. As Zembylas writes, attending to and through matters of affect can provide a way of getting to the ethical and political implications of the material, because attending to "affect opens up possibilities that may cultivate political and ethical relating in the classroom" (Zembylas 2006, 308). Let us take a minute to think about what that means: Could a class on serial killers, taught in such a way that it registered the affect of the material, change the way the students in the class related to each other? Could affect be used to teach tenderness to each other's feelings-rather than reinforcing the message of 'stranger danger' and 'victim facilitation'? Could affect be used in this class to strengthen lines of empathy and communication, such that, maybe, if we have a burgeoning psychopath in our midst-as is statistically likely, given there is said to be 1 psychopath in every 100 people, and the class has nearly 200 students-then maybe speaking through and with affect could provide an opening for them. A chance for self-reflection and a community with which to do it.

\section{In Closing and Opening}

Since we dove into the realms of affect theory and the spaces of affect-are they caverns or are they oceans?-then it is only appropriate that we climb out of the immersion to catch our breath and reevaluate where we are and where we were. This article provided beginning introspections on three sites of affective immersion. It was about witnessing as the Jewish inheritance and of the Jewish inheritance, a witnessing that occurs through affectively embodying and emulating ancestors. It was about the affectively charged space-between that is theoretically generated by the sharing of trauma, and the seeming impossibility of an adequate response. And it was about a classroom that attends to violence while painfully ignoring affect. Yet to end we inevitably have more questions: Does each site exemplify affect in the same way? And what do these small, fragmentary moments reveal about affect?

If affect is the flowing within and between bodies of certain intensities, each site does not, and would not, manifest affect in the same way. Instead, each site exemplifies a different aspect of a theory that still largely eludes us. Yet affect theory also opens up something in these moments that couldn't be understood 
without attention to affect. In the first site, listening to the way Jewish tradition teaches Jews to keep the past alive, affect becomes something that is felt through intentional repetition, from collapsing time, and from making a role for the young in the intergenerational transmission of trauma. Affect is experienced inside bodies, and affect is shared between them. In the same way, affect is in the audience shifting in discomfort and the searing gaze of the survivor-and it is also between them. So that what is shared is more than her story and more than the tenuous response and meager action her story elicits. Instead, the affect inside that room brings everyone to the same tremulous plane of feeling. It links the room in a different way, in a way that supersedes what is verbally acknowledged. And lastly, the affect that is ignored by the both sensational and dull memorization of startling violence leaves a gap, a fissure, in how we can use that information proactively and effectively.

Eve Sedgwick writes that the most useful work "occurs near the boundary of what a writer can't figure out how to readily say" (Sedgwick 2003, 4). There is a certain power in existing on the boundaries of what can't be fully articulated. It forces us to bypass the brain's conscious apprehension, because maybe affect is not the stuff of words, even though we have just expended so many in our effort to unearth it. As such, the pages you have before you do not presume an absolute coherence in word and idea. But from them, and together, I hope we opened up these seemingly disparate moments and this confounding theory in order to feel that 'something' that imbues the air, our bodies, and the spaces between us. Moving forward in a complex and confusing world, we need to intuit how affect links us to each other. We need to open our senses to it, because attending to affect allows us to glimpse spaces and openings and needs that might otherwise be invisible. 


\section{References}

Adler, David A. (1987). The Number on my Grandfather's Arm. New York: URJ Press.

Adelson, Robert. A. (2005). Haggadah Ha Shoah: Retelling the Holocaust Story as Haggadah Supplement before Retelling the Exodus at Passover. [online] Business Law Blog by Robert Adelson, Esq. Available at: https://robadelson. wordpress.com/haggadah-ha-shoah/ [ 14 April 2015]

Ahmed, Sara. (2004 a). Affective Economies. Social Text, 22 (2), pp. 117-139.

-(2004 b). The Cultural Politics of Emotion. London: Routledge.

-(2010). The Promise of Happiness. Durham, NC: Duke University Press.

Angelou, Maya. (1993). Inaugural Poem: On the Pulse of Morning. London: Random House.

Bankhead, Rashinda. (2014). Student-led club brings Rana Plaza survivor to ASU, denounces VF Corporation school ties. The State Press. April 10, 2014.

Boler, Megan. (1999). Feeling Power Emotion and Education. New York: Routledge.

Brennan, Teresa. (2004) The Transmission of Affect. Ithaca: Cornell University Press.

Caruth, Cathy. (1995). Trauma and Experience: Introduction. Trauma: Explorations in Memory. Edited by Caruth, Cathy. Baltimore and London: Johns Hopkins University Press.

Caruth, Cathy. (1996). Unclaimed Experience: Trauma, Narrative, and History. Baltimore: Johns Hopkins University Press.

Casper, Monica and Eric Wertheimer. (2016). Critical Trauma Studies: Understanding Violence, Conflict and Memory in Everyday Life. New York: NYU Press.

Cho, G. (2008). Haunting the Korean Diaspora. Minneapolis: University of Minnesota Press.

Dahlbeck, J. (2014). Towards a Pure Ontology: Children's Bodies and Morality. Educational Philosophy and Theory, 46 (1), pp. 8-23.

Dutro, Elizabeth and Bien, Andrea C. (2014). Listening to the Speaking Wound: A Trauma Studies Perspective on Student Positioning in Schools. American Educational Research Journal, 51 (1), pp. 7-35. 
Gilmore, Leigh. (2001). The Limits of Autobiography: Trauma and Testimony. Ithaca, N.Y.: Cornell University Press.

Gordon, Avery. (1997). Ghostly Matters Haunting and the Sociological Imagination. Minneapolis: University of Minnesota Press.

Gunew, Sneja (2009). Subaltern Empathy: Beyond European Categories in Affect Theory. Concentric: Literary and Cultural Studies 35 (1), pp. 11-30.

Felman, Shoshana and Laub, Dori. (1992). Testimony: Crises of Witnessing in Literature, Psychoanalysis, and History. New York and London: Routledge.

Hirsch. Marianne. (1992). Family Pictures: Maus, Mourning, and Post-Memory. Discourse: Special Issue: The Emotions, Gender, and the Politics of Subjectivity. 15 (2), pp. 3-29.

Hochschild, Arlie Russell. (1983). Managed Heart: Commercialization of Human Feeling. Berkeley, C.A.:University of California Press.

Kaplan, A. E. (2005). Trauma Culture: The Politics of Terror and Loss in Media and Literature. Rutgers, NJ: Rutgers University Press.

LaCapra, Dominick (2000). Writing History, Writing Trauma. Baltimore: John Hopkins University Press.

Levi, Primo. (1969). Survival in Auschwitz. London: Collier-Macmillan.

Levins, Morales, A. (2013). Kindling. Cambridge, MA: Palabrera Press.

Leys, Ruth. (2000). Trauma: A Genealogy. Chicago: University of Chicago Press.

-(2011). The Turn to Affect: A Critique. Critical Inquiry. 37 (3), pp.434-472.

Lutz, Catherine. (1986). Emotion, Thought, and Estrangement: Emotion as a Cultural Category. Cultural Anthropology 1 (3), pp. 287-309.

Massumi, Brian. (1995). The Autonomy of Affect. Cultural Critique. 31 (3). pp. 83-109.

Million, Dian. (2013). Therapeutic Nations: Healing in an Age of Indigenous Human Rights. Tuscon: The University of Arizona Press.

Murphie, Andrew. (2010). Affect-A Basic Summary of Approaches. [online] Adventures in Jutland. Available at: http://www.andrewmurphie.org/ blog/?p=93 [Accessed 5 Jan. 2016].

Oliver, Kelly. (2001). Witnessing: Beyond Recognition. Minneapolis: University of Minnesota Press. 
Owen, A. Susan \& Ehrenhaus, Peter. (2010). Communities of Memory, Entanglements, and Claims of the Past on the Present: Reading Race Trauma through The Green Mile. Critical Studies in Media Communication, 27 (23), pp.131-154.

Ozeki, Ruth L. (2017). A Tale For the Time Being. Melbourne, Vic.: The Text Publishing Company.

Pratt, Minnie Bruce. (2001). Who Am I If I'm not My Father's Daughter? A Southern Confronts Racism and Anti-Semitism. In: Identity Politics in the Women's Movement. Edited by Barbara Ryan. New York: NYU Press.

Sedgwick, E. (2003). Touching Feeling: Affect, Pedagogy, Performativity (Series Q). Durham: Duke University Press.

Seigworth, Gregory and Gregg, Melissa. (2010). An Inventory of Shimmers. In Seigworth, Gregory and Gregg, Melissa, eds. The Affect Theory Reader. Durham: Duke University Press.

Seltzer, Mark. (1997). Wound Culture: Trauma in the Pathological Public Sphere. October, 80, pp. 3-26.

Shouse, Eric. (2005). Feeling, Emotion, Affect. M/C Journal 8 (6).

Simon, R. and Eppert, C. (1997). Remembering Obligation: Pedagogy and the Witnessing of Testimony of Historical Trauma. Canadian Journal of Education / Revue canadienne de l'éducation, 22 (2), p.175-191.

Stewart, Kathleen. (2007). Ordinary Affects. Durham, NC: Duke University Press. Thrift, Nigel. (2004). Intensities of Feeling: Towards a Spatial Politics of Affect. Geografiska Annaler, 57 -78.

White, Daniel. (2017). Affect: An Introduction. Cultural Anthropology, 32 (2), pp. $175-180$.

Wiesel, Elie. (1986). Nobel Peace Prize Speech. In Night. New York: Hill and Wang.

Zembylas, M. (2006). Witnessing in the Classroom: The Ethics and Politics of Affect. Educational Theory, 56 (3), pp.305-324. 